\title{
A multirreferencialidade de saberes nos atos de mediação do conhecimento: o aporte das ciências cognitivas à ação pedagógica das bibliotecas
}

Aida Varela Varel

Doutora em Ciências da Informação pela Universidade de Brasília Professora adjunta da Universidade Federal da Bahia.

Marilene Abreu Barbosa

Mestre em Ciência da Informação pelo Instituto de Ciência da Informação da Universidade Federal da Bahia . Professora da Universidade Federal da Bahia.

Analisam-se as exigências dos novos tempos para o acesso ao conhecimento, em termos de cognição competências e habilidades. Revisam-se conceitos de analfabetismo, alfabetismo e privação cultural, e a função da Educação e da Biblioteconomia no processo de aprendizagem, tendo em vista o desenvolvimento de competências informacionais, fundamentando-se em estudos sobre cognição, mediação, multirreferencialidade. Objetiva-se $o$ entendimento da complexidade dos fenômenos sociais e das vantagens que podem advir do entrelaçamento das diversas áreas do conhecimento na resolução de problemas relativos ao acesso do conhecimento.

Palavras-chaves: Acesso ao conhecimento; Multirreferencialidade; Mediação e Cognição; Bibliotecas.

\section{The Knowledge multirange in mediation acts: cognitive sciences contributions to libraries pedagogics actions}

This article analyzes the new demands for the access to knowledge, in terms of cognition - competences and 
abilities. Basic concepts are reviewed such as illiteracy, literacy and cross culture and the role of education and librarianship in the learning process, focusing on development of informational competences based on cognition, mediation and multirange studies. The articule aims to understand the complexity of social phenomena and the benefits that may arise from the intertwining of the various areas of knowledge in solving problems related to access to knowledge.

Keywords: Knowledge access; Multirange; Mediation and cognition; Libraries.

Recebido em 30.12.2008 Aceito em 24.07.2009

\section{Introdução}

Novos tempos apontam para o desenvolvimento de um conjunto de competências e de habilidades, a fim de que se possa, efetivamente, compreender e refletir sobre a realidade, participar e agir no contexto de uma sociedade em que o conhecimento é construído pelas interações contínuas realizadas individualmente pelo cidadão e validados coletivamente por todos os cidadãos. Assim, os conceitos, as idéias, as leis, as teorias, os fatos, as pessoas, a história, o espaço geográfico, as manifestações artísticas, os meios de comunicação, a ética, a política, os governos, os valores etc. - traduzidos nos conteúdos formais das ciências, das artes e da filosofia - constituem-se em um conjunto de condições essenciais à construção do conhecimento (MINISTÉRIO DA EDUCAÇÃO E CULTURA (MEC); INSTITUTO NACIONAL DE ESTUDOS E PESQUISAS EDUCACIONAIS ANÍSIO TEIXEIRA (INEP), 2007).

$\mathrm{Na}$ atualidade, tem-se chamado a atenção para a exclusão digital, no sentido de que ela significa a exclusão do conhecimento e, deste modo, retira das pessoas a possibilidade de mudar suas vidas e de participar democraticamente das decisões importantes para o desenvolvimento pleno do país. De fato, as tecnologias de informação e comunicação se transformaram em requisitos fundamentais para a educação transformadora e inclusiva, passando a ser preocupação dos governos e órgãos supranacionais, conforme expressa a Declaração Ministerial do Conselho Econômico e Social da ONU, de 2000, que assegura: "velar para que todos possam aproveitar os benefícios das novas tecnologias, em particular das tecnologias da informação e das comunicações".

No entanto, a questão é mais complexa. O homem do século XXI está diante de situações-problema, e enfrentá-las implica selecionar, organizar, relacionar e interpretar dados para tomar decisões, fazendo-se necessário um recorte significativo de uma realidade, que pode ser analisada sob várias óticas e que pode conter fatores concorrentes, no 
sentido de que nem sempre é possível dar prioridade a todos eles ao mesmo tempo (MEC; INEP, 2007).

Nesta perspectiva, pode-se inferir que, para se chegar ao conhecimento, não basta o acesso físico às tecnologias, mas, sobretudo, é preciso estimular os múltiplos processos cognitivos, a mediação e a contextualização que se constituem pré-requisitos para apreender e compreender conteúdos formativos e informativos. Compreender fenômenos significa ser competente para formular hipóteses ou idéias sobre as relações causais que os determinam. Para isto, é importante que se estabeleçam relações e inferências, produto de análises e reflexões indispensáveis ao processo de aprendizagem.

Numa sociedade que está aberta para todas as possibilidades de conhecimento, os países revisam seus modelos educacionais, discutem e implementam reformas curriculares mais apropriadas, que privilegiam a noção de um processo dinâmico de desenvolvimento cognitivo; encarando a inteligência, não como uma faculdade mental ou como expressão de capacidades inatas, mas como uma estrutura de possibilidades crescentes de construção de estratégias básicas de ações e operações mentais, com as quais se constróem os conhecimentos. Para tanto, entende-se que, não apenas a escola, mas a biblioteca, as tecnologias da informação e muitos outros espaços e recursos educativos, devem mediar as possibilidades de formação plena do indivíduo e de sua inserção na sociedade.

Propõe-se, aqui, analisar as exigências dos novos tempos para o acesso ao conhecimento, em termos de cognição - competências e habilidades -; o descompasso de uma camada da população brasileira à luz das pesquisas sobre analfabetismo e alfabetismo; além de incentivar a reflexão sobre novas perspectivas para a organização e a difusão do conhecimento, fundamentada em estudos sobre cognição, mediação e multirreferencialidade, para entender a complexidade dos fenômenos sociais e o fortalecimento da atividade científica.

As análises e reflexões apresentadas evidenciam a relevância da integração da Biblioteconomia e da Ciência da Informação com as ciências cognitivas, tendo em vista que, cada vez mais, os profissionais destas áreas precisam lidar diretamente com as estratégias mentais de apreensão e compreensão da informação, ou seja, com o processo de construção pelo qual transita o sujeito aprendiz e transformador do mundo.

\section{Descompasso no acesso ao conhecimento}

A questão que se põe atualmente é se o acesso e a freqüência à escola são suficientes para garantir a aquisição de habilidades necessárias à vida pessoal e profissional, bem como o desenvolvimento de cidadãos conscientes de direitos e deveres. Por outro lado, outra questão está relacionada à reparação da exclusão educacional de milhões de cidadãos que já ultrapassaram a idade da escolarização regular e que não concluíram a educação básica. Para refletir sobre essa situação, 
apresentam-se e analisam-se os resultados do Indicador de Alfabetismo Funcional (INSTITUTO PAULO MONTENEGRO, 2007).

O INAF, criado e implementado pelo Instituto Paulo Montenegro, disseminador de práticas educacionais inovadoras, e pela ONG Ação Educativa, vem sendo realizado desde 2001 e aplicado por amostragem a 2000 pessoas, entre 15 e 64 anos, residentes em zonas urbanas e rurais de todas as regiões do Brasil. O INAF trabalha com o termo "letramento", correspondente ao termo em inglês literacy, que diz respeito à condição de pessoas ou grupos sociais de fazer uso da linguagem escrita. O termo Alfabetismo considera os dois domínios: letramento (processamento de informação verbal em diversos formatos; compreensão e expressão escrita) e numeramento, capacidade de compreender e operar com noções e representações matemáticas envolvidas em situações cotidianas.

Com base na análise das tarefas, O INAF definiu quatro níveis de alfabetismo (INSTITUTO PAULO MONTENEGRO, 2007):

1. Analfabetismo: condição dos que não conseguem realizar tarefas simples que envolvem a leitura de palavras e frases, ainda que uma parcela destes consiga ler números familiares (números de telefone, preços etc.);

2. Alfabetismo nível rudimentar: as pessoas apresentam capacidade de localizar uma informação explícita em textos curtos e familiares (como um anúncio ou pequena carta), ler e escrever números usuais e realizar operações simples, bem como de manusear dinheiro para o pagamento de pequenas quantias ou fazer medidas de comprimento usando a fita métrica;

3. Alfabetismo nível básico: as pessoas podem ser consideradas funcionalmente alfabetizadas, pois já lêem e compreendem textos de média extensão, localizam informações mesmo que seja necessário realizar pequenas inferências, lêem números na casa dos milhões, resolvem problemas envolvendo uma seqüência simples de operações e têm noção de proporcionalidade. Mostram, no entanto, limitações quando as operações requeridas envolvem maior número de elementos, etapas ou relações;

4. Alfabetismo nível pleno: as pessoas apresentam habilidades para compreender e interpretar elementos usuais da sociedade letrada: lêem textos mais longos, relacionando suas partes, comparam e interpretam informações, distinguem fato de opinião, realizam inferências e sínteses. Quanto à matemática, resolvem problemas que exigem maior planejamento e controle, envolvendo percentuais, proporções e cálculo de área, além de interpretar tabelas de dupla entrada, mapas e gráficos. 
Os resultados mostram que nem sempre o nível de escolaridade garante o nível de habilidades que seriam esperadas, uma vez que: 64\% dos brasileiros entre 15 e 64 anos que estudaram até a $4^{a}$ série atingem 0 grau rudimentar de alfabetismo; $12 \%$ dos $64 \%$ são considerados analfabetos absolutos em termos de habilidades de leitura/escrita, não decodificam palavras e frases e apresentam dificuldades em lidar com números em situações do cotidiano, apesar de terem cursado os quatro anos do Ensino Fundamental; dos que cursaram da $5^{a}$ a $8^{a}$ série, apenas $20 \%$ podem ser considerados plenamente alfabetizados, enquanto que a maioria se enquadra no nível básico de alfabetismo.

Observe-se que $26 \%$ dos que completaram entre a $5^{a}$ a $8^{a}$ séries ainda permanecem no nível rudimentar; enquanto $47 \%$ dos que cursaram ou estão cursando o Ensino Médio atingem o nível Pleno de Alfabetismo (esperado para $100 \%$ deste grupo) e praticamente $45 \%$ permanecem no nível básico; somente entre os que chegaram ou completaram o Ensino Superior é que prevalecem (74\%) os indivíduos com pleno domínio das habilidades de leitura/escrita e das habilidades matemáticas.

O INAF retrata, também, a distribuição dos diferentes níveis de alfabetismo pelo território brasileiro, evidenciando contrastes e diferenças regionais: a população do Sul tem níveis mais altos de alfabetismo, com $71 \%$ funcionalmente alfabetizados, sendo $1 / 3$ de forma plena; a Região Nordeste apresenta maior contingente de analfabetos funcionais, correspondente a 46\% da população entre 15 e 64 anos; e há semelhança no perfil da população das regiões Sul e Sudeste (maior concentração no nível básico, um número reduzido de analfabetos e proporções equivalentes entre os níveis rudimentar e pleno).

Confirmando os indicadores do INAF, o Instituto Brasileiro de Geografia e Estatística (IBGE) (2004-2005) declara que 11,4\% das pessoas com mais de 15 anos são analfabetos e $23,5 \%$ são analfabetos funcionais, ou seja, são considerados alfabetizados mas não têm capacidade de ler e interpretar informações. Do total da população com mais de 10 anos de idade, $11,3 \%$ não possuem instrução ou têm menos de um ano de estudo e apenas $26 \%$ possuem 11 ou mais anos de estudo (IBGE, 2004-2005). Os números do IBGE mostram que, no geral, a população brasileira não possui um alto grau de instrução e, provavelmente, não domina as tecnologias da informação.

O INAF mostra ainda que a maioria dos alfabetizados no nível rudimentar e básico não costuma ler livros (29\% e $16 \%$ ) ou só lêem um tipo $(42 \%)$, geralmente a bíblia ou livros religiosos. A leitura dos alfabetizados no nível pleno é diversificada (33\% lêem dois gêneros e $34 \%$ três ou mais). Buscando enriquecer esses dados, nas edições de 2003 e 2005, o INAF perguntou aos entrevistados se já estiveram numa biblioteca e onde. Os resultados mostram que houve uma diminuição no número daqueles que já estiveram numa biblioteca pública (de $59 \%$ para $49 \%$ ), mas aumentou um pouco o número dos que já estiveram numa biblioteca escolar (45\% para 49\%). A análise multivariada dos dados do 
INAF mostrou que a freqüência a mais de um tipo de biblioteca é um diferencial importante nos níveis de alfabetismo.

Os resultados apresentados pelo INAF, ao longo do período 20012007, mostram que é preciso investir na qualidade de modo que a escolarização garanta, de fato, as aprendizagens necessárias para que os cidadãos se insiram de forma autônoma e responsável na sociedade contemporânea. É também de grande importância analisar a função atribuída à biblioteca para subsidiar o processo de alfabetismo/analfabetismo que vem ocorrendo na Educação Brasileira.

Uma nova qualidade precisa ser construída, considerando as demandas de uso da leitura, escrita e matemática, não só para a continuidade dos estudos, mas para se inserir de forma eficiente e autônoma no mundo do trabalho e do exercício da cidadania. O que vem sendo exposto e analisado pode ser assim sintetizado:

Não é viável enfrentar a inclusão digital sem levar em conta o alto índice de analfabetismo. Embora o combate ao analfabetismo no país conte com a participação de vários segmentos da sociedade, os recursos governamentais ainda são insuficientes, sem contar que os recursos humanos ainda são escassos, pois os profissionais da área não atuam diretamente na promoção da educação e do bem-estar social. Por formação o bibliotecário é altamente qualificado para desempenhar o papel social que promova a cidadania em comunidades carentes. Porém, são poucos os que se interessam pela área, já que não há retorno quanto à remuneração e a infra-estrutura oferecida é desfavorável para uma atuação efetiva (BAPTISTA, 2006, p. 6).

\section{Bibliotecas, cognição, mediação e privação cultural: reflexões}

O cenário tecnológico põe em crise a tipologia convencional de bibliotecas - nacionais, especializadas, universitárias, públicas e suas derivações -, exaustiva e amplamente definida na literatura biblioteconômica (LEITE; MIRANDA; SUAIDEN, 2008), pois, em virtude das mídias integradas e dos suportes eletrônicos disponíveis, todos os tipos de biblioteca podem oferecer todos os tipos de serviços, como concluem Garcez e Rados:

A biblioteca híbrida é designada para agregar diferentes tecnologias, diferentes fontes, refletindo o estado que hoje não é completamente digital, nem completamente impresso, utilizando tecnologias disponíveis para unir, em uma só biblioteca, o melhor dos dois mundos (o impresso e o digital) (GARCEZ; RADOS, 2002, p. 47). 
Ao examinar estas novas tendências, toma-se conhecimento do patamar e de parâmetros biblioteconômicos de ordem internacional avançados, que já subsidiam o processo educacional a partir da educação básica, em consonância com o exercício gradual de democracia e a formação de consciência de cidadania, que habilitam os estudantes para discussões sociais locais, nacionais e internacionais. Abre-se então uma questão: O que se está enunciando, internacionalmente, pode ser aplicado igualmente em ambientes brasileiros, principalmente nos pontos menos desenvolvidos do país?

\subsection{A ação educativa das bibliotecas}

Historicamente, as bibliotecas, a exemplo da biblioteca de Alexandria e de Nínive, reuniam e custodiavam valiosos acervos documentais para contar a saga da humanidade. A biblioteca pública surge por volta de 1850 na Inglaterra, para aculturar a classe operária da Revolução Industrial, melhorando a qualidade da mão-de-obra operária. A biblioteca foi se ampliando e absorvendo papéis, estando comprometida, nos dias atuais, com quatro funções básicas, a educacional, a cultural, a de lazer ou recreacional, e a informacional; esta última surgida no final da década de 60 do século passado, como reflexo do papel que a informação ganhou na vida e na economia contemporâneas.

A UNESCO, a IFLA (Federação Internacional de Associações e Instituições Bibliotecárias), o SNBP (Sistema Nacional de Bibliotecas Públicas), bem como movimentos políticos e sociais, atribuem à biblioteca pública o papel de promotora da educação e da cultura, e difusora de informação e de conhecimento, em sentido amplo. A biblioteca pública é, potencialmente, capaz de contribuir para a ampliação e o fortalecimento educacional.

A biblioteca pública é o centro local de informação, disponibilizando prontamente para os usuários todo tipo de conhecimento; os serviços fornecidos por ela baseiam-se na igualdade de acesso para todos, independentemente de idade, raça, sexo, religião, nacionalidade, língua ou status social (BIBLIOTECA PÚBLICA, 2000, p. 21).

No Brasil, a biblioteca pública tem-se destacado pela prática da educação continuada, valendo-se, principalmente, de programas de promoção da leitura, buscando contribuir para erradicar o analfabetismo e consequentemente promover a inserção do indivíduo na sociedade. As tecnologias da informação facilitam o trabalho educativo da biblioteca pública e proporcionam o cumprimento integral de sua missão de educar e disseminar o conhecimento.

Gomes (1999, p. 3) considera que educar é o objetivo primordial de qualquer biblioteca. Ela afirma que "a biblioteca é um instrumento de ensino universal e reúne e distribui livremente todos os instrumentos da 
educação e, com sua ajuda, dissemina o conhecimento. Este é o espírito da biblioteca".

Este ato de educar se concretiza sempre que o bibliotecário, na interação com o usuário, busca com ele encontrar a informação pertinente para atender à sua necessidade de estudo, pesquisa ou solução de um problema complexo ou do cotidiano. A missão educativa da biblioteca evidencia-se nos serviços de referência, que, por meio dos programas de educação do usuário, passaram a capacitar seu público no manuseio da biblioteca e de suas coleções. Estes programas, usados intensamente em bibliotecas públicas e escolares, fundamentaram-se em teorias pedagógicas, aproximando a biblioteca da escola, e criaram as bases para a implantação do atual movimento da information litteracy. Le Coadic (2004, p. 112) refere-se à "educação para a informação", ponderando sobre a complexidade do universo informacional na atualidade, no qual o sujeito precisa "aprender a se informar e aprender a informar", tarefas educativas a serem assumidas pela biblioteca pública, no âmbito da educação permanente, e pela biblioteca escolar, no apoio à formação do sujeito.

Nos últimos 25 anos, com a expansão das tecnologias de informação e comunicação, os estudos de usuários têm focado com mais intensidade a compreensão dos tipos de comportamento informacional humano, e remetem a conceitos como: contextos informacionais, necessidades informacionais, comportamentos de busca da informação, modelos de acesso à informação, recuperação, disseminação, processamento e uso da informação. Tudo isso com a crença de que a informação seja essencial ao funcionamento e à interação dos indivíduos, grupos sociais, organizações e sociedades, além de ter o potencial para transformar o conhecimento e subsidiar decisões e ações (TODD, 2003, apud FIALHO; ANDRADE, 2007).

É crescente a literatura sobre o comportamento informacional em várias partes do mundo. Pesquisas sobre biblioteca escolar revelam que ela tem aparecido como agente fundamental no processo de aprendizado quando sua proposta está integrada ao currículo escolar. Ela se apresenta como um elemento importante no desenvolvimento da competência informacional que envolve diversas habilidades, contribuindo diretamente para a formação crítica e reflexiva dos sujeitos. Embora ainda estejam em estudo critérios de medição e avaliação dos reais efeitos dos programas de biblioteca escolar sobre o aprendizado de estudantes, existem avaliações, em outros países, que comprovam os efeitos positivos destes programas, como, por exemplo:

1. O estudo de Baughman (2000, apud FIALHO; ANDRADE, 2007) aponta que, em Massachusetts, 92\% das escolas públicas possuem bibliotecas escolares. Os itens avaliados foram staff, acervo e infra-estrutura tecnológica das bibliotecas. Ficou comprovado que as notas dos estudantes são mais elevadas onde há escolas com programas de bibliotecas que apresentam um bom número de livros por 
estudante e com uso intenso, além de horários flexíveis e programas instrucionais. Bibliotecas onde há maior investimento de materiais por estudante, onde eles são atendidos por um bibliotecário em tempo integral juntamente com o auxílio do staff, onde há coleções automatizadas e quando a biblioteca está ajustada com a estrutura curricular da escola, subsidiam, certamente, o fortalecimento do processo ensino-aprendizagem;

2. Na Austrália, Lonsdale (2003, apud FIALHO; ANDRADE, 2007) sugere que as bibliotecas escolares, para ter impactos positivos sobre as atividades estudantis, devem apresentar as seguintes características: programa de biblioteca potente, adequadamente assistido, planejado e fundamentado para conduzir a melhoria da atividade estudantil, independentemente dos níveis socioeconômicos ou educacionais dos adultos na comunidade; rede de computador potente conectando recursos da biblioteca à sala de aula e laboratórios; qualidade da coleção; incentivo para o uso da biblioteca escolar; relacionamentos colaborativos entre professores e bibliotecários escolares, particularmente em relação ao planejamento de unidades instrucionais, desenvolvimento de coleções e subsídio para o desenvolvimento profissional de professores.

Registra-se que: a) quanto mais rica a coleção de impressos, mais incentivo existe para a leitura, o que culmina com o desenvolvimento da compreensão, crescimento do vocabulário, habilidades ortográficas, gramaticais e estilo de escrita; b) a integração das habilidades informacionais ao currículo escolar pode proporcionar aos estudantes domínio de conteúdo e das habilidades de busca da informação; c) as bibliotecas podem fazer uma diferença positiva na auto-estima dos estudantes, no sentimento de confiança, na independência e no senso de responsabilidade em relação ao seu próprio aprendizado.

De acordo com Todd (2003, apud FIALHO; ANDRADE, 2007), um aspecto consistente que emerge de todos esses estudos é a necessidade de desenvolver competências informacionais e críticas nos aprendizes, desenvolvendo as bases intelectuais para que possam usar apropriadamente a informação, questioná-la, criticá-la e acessá-la.

Neste contexto, as bibliotecas vêm se constituindo imprescindíveis ao desenvolvimento de uma sociedade letrada e se impõem como instituição chave de uma sociedade igualitária, ao garantir o exercício de um direito cidadão básico.

O atual sistema educativo necessita passar por mudanças principalmente no Brasil, onde, em termos concretos, não existem bibliotecas escolares atuantes e articuladas com as necessidades pedagógicas - para adaptar-se à realidade do século XXI, de igual maneira que outros setores estratégicos da sociedade, replanejando procedimentos 
de ensino-aprendizagem. O centro dessa mudança poderia dar-se por meio da biblioteca escolar, que, mediante modelo funcional e organizativo, se transformaria em um recurso estratégico dinamizador do currículo, com uma participação ativa no processo pedagógico, assumindo o processo de alfabetização informacional, fundamentando-se em princípios de cognição e mediação.

\subsection{Cognição e mediação: visões teóricas}

Com base nos dados apresentados pelo INSTITUTO PAULO MONTENEGRO (2007) e na análise sobre o papel da escola - oferecer aos alunos habilidades e competências necessárias para o desenvolvimento pessoal, social e profissional - e da biblioteca escolar - espaço em que os alunos encontram material para complementar sua aprendizagem e desenvolver sua criatividade, imaginação e senso crítico -, faz-se necessário ressaltar a importância dos estudos teóricos sobre a área da aprendizagem com foco na cognição humana, para subsidiar a formação de professores e bibliotecários.

O estágio de desenvolvimento cognitivo, correspondente à etapa da Educação Básica (composta pela Educação Infantil, Ensino Fundamental e Ensino Médio) no Brasil, caracteriza-se pelo período das operações formais, marcado pelo advento do raciocínio hipotético-dedutivo. Para Piaget (1987), ao atingir esse período, os jovens podem considerar o real como uma ocorrência entre múltiplas e exaustivas possibilidades. A estrutura mental e o conhecimento são construídos em uma relação dialética entre a maturação biológica e o ambiente.

Vigótski (1991) concede importância fundamental ao desenvolvimento da linguagem, sendo a palavra um rico instrumento para transmitir a experiência histórica da humanidade. O conhecimento constitui-se numa produção cultural, diretamente relacionada com a linguagem e com a interação social. No que se refere à mediação, Vigótski (1991) ressalta as relações culturais de mediação das estruturas psicológicas. O fator decisivo no desenvolvimento não recai sobre o indivíduo, sujeito dos processos de construção intelectual, mas sobre os processos de mediação das estruturas cognitivas e lingüísticas. A mediação é a ação que se interpõe entre sujeito e objeto de aprendizagem, sendo a palavra de fundamental importância.

No conjunto da obra de Paulo Freire, são destacados elementos ontológicos/epistemológicos, entre eles o conceito de educação dialógica versus educação bancária. Na educação bancária, duas estruturas se confrontam: a do educador que sabe e comunica e a do educando que não sabe e aprende. E na educação dialógica, dois processos de estruturação gnosiológica interagem, um ensinando / aprendendo com o outro e ambos construindo o conhecimento do mundo. Para Paulo Freire (1979), mediação é a ação por meio da qual o homem chega a ser sujeito por uma reflexão sobre sua situação, sobre seu ambiente concreto. "Quanto mais o 
homem reflete, mais ele emerge e compromete-se para intervir na realidade".

Feuerstein, ao desenvolver a Teoria da Modificabilidade Cognitiva Estrutural (TMCE) e da Experiência de Aprendizagem Mediada (EAM), explica a aprendizagem humana emergindo de uma relação indivíduomeio, mediatizada por outro indivíduo mais experiente, cujas práticas e crenças culturais são transmitidas, promovendo zonas mais amplas de desenvolvimento crítico e criativo, rumo à autonomia cognitiva, decorrente de uma aprendizagem mediada (FEUERSTEIN, 1980).

Quando o mediador é o professor, ele põe em prática estratégias de mediação na apresentação das várias tarefas inerentes ao processo ensino-aprendizagem, visando à generalização e à abstração conceitual. No entanto, o processo de mediação transcende à sala de aula, alcançando a biblioteca e outros ambientes de aprendizagem.

Segundo Morin (2000), um conhecimento pertinente deve enfrentar a complexidade que se dá quando elementos diferentes, constitutivos do todo, são inseparáveis; e aponta que a capacidade de aprender está ligada ao desenvolvimento das competências inatas do indivíduo de adquirir conhecimentos e, ainda, assinala que a mediação é o diálogo/interação de ordem e desordem do mundo, tecendo as partes e o todo, o todo e as partes e as partes entre si.

O que se apreende a partir desta revisão sobre aprendizagem e mediação, portanto, é que os estudos sobre a cognição humana se caracterizam como um fenômeno multirreferencial, de alta complexidade, que envolvem várias atividades mentais. Com estas considerações, uma grande preocupação recai nos riscos da sociedade em trazer, como conseqüências, a partilha desigual de conhecimentos e competências, ampliando-se a exclusão social, acentuando-se as desigualdades já existentes entre setores e regiões de maior e menor renda.

Vale destacar que o princípio de igualdade de oportunidade, registrado nos manifestos da UNESCO para as bibliotecas pública e escolar, base igualitária de cidadania, ampara as discussões sobre a ação das bibliotecas na formação de uma sociedade com lastro educativo e cultural mais abrangente e sólido. Assim, o conhecimento tornar-se-ia um dos principais fatores de superação de desigualdades e a universalização das bibliotecas ajudaria a viabilizar o acesso equitativo à informação, ressaltando-se a responsabilidade dos profissionais bibliotecários na aquisição, atualização e utilização dos conhecimentos, que correspondem às três funções do processo educativo, ao lado do desenvolvimento de aptidões intelectuais e cognitivas para pessoas a serem formadas para a inovação, para o mundo plural e em constantes transformações.

\subsection{Cognição e inteligência no processo de leitura}

Wittrock afirma que "para compreender um texto, nós não apenas o lemos, no sentido literal da palavra: nós construímos um significado para ele". Assim procedendo, os leitores "criam imagens e transformações 
verbais para representar seu significado. E o que é mais impressionante: eles geram significado à medida que lêem, construindo relações entre seu conhecimento, sua memória da experiência, e as frases, parágrafos e trechos escritos" (WITTROCK, 1991, apud MANGUEL, 1997, p. 54).

Por meio de exercícios constantes de leitura, de análise e de compreensão do texto, pode-se ambicionar o incremento de uma atitude "decifradora" em relação à inteira realidade; ou de uma atitude criadora, estimulando nos leitores uma espécie de impulso exegético que se estenda ao universo extratextual e se transforme em desejo de sentido. Assim, talvez, se possa incentivar a habilidade de captar e compreender as interdependências, a multiplicidade e a complexidade do real. Porque, definitivamente

É sempre o leitor que lê o sentido; é o leitor que confere a um objeto, lugar ou acontecimento, uma certa legibilidade possível, ou que a reconhece neles; é o leitor que deve atribuir significado a um sistema de signos e depois decifrá-lo. Todos nós lemos a nós e o mundo à nossa volta para vislumbrar o que somos e onde estamos. Lemos para compreender, ou para começar a compreender. Não podemos deixar de ler. Ler, quase como respirar, é nossa função essencial (MANGUEL, 1997, p.19-20).

Com base nas pesquisas da teoria literária, da lingüística, da antropologia simbólica, da psicologia cognitiva e da psicologia evolutiva, Bruner (1997) examina os atos mentais que se inscrevem na criação imaginativa de mundos possíveis, e demonstra que a atividade do imaginário permeia, ao mesmo tempo, as ciências humanas, a literatura e a filosofia, alcançando inclusive a percepção do eu.

Para Bruner (1997), o pensamento narrativo é aquele pensamento que constrói infinitos mundos possíveis com a linguagem, imagens, invenções e, sobretudo, com a memória autobiográfica; é a essência de nossa própria natureza. Em Atos de Significação, o autor sustenta que a revolução cognitiva, como havia sido originalmente concebida, comportava a possibilidade de que a psicologia cooperasse com a antropologia, a lingüística, a filosofia e a história, e "inclusive com as disciplinas jurídicas" (BRUNER, 1997, p. 16-17).

Em síntese, para que se possa entender o fenômeno da vida, que em si mesmo se constitui na base que fundamenta a incessante, permanente e mutável busca da ciência, é importante que se reconheça a total interdependência entre o indivíduo, o outro e a natureza, pois são mutuamente inclusivos. Nessa perspectiva, D'Ambrosio (2000) mostra que, por meio de instrumentos e tecnologia, a espécie humana estabelece diferentes vínculos entre o sujeito e a natureza. Em decorrência de sua produção e trabalho, cria intermediações entre a natureza e os outros e, por meio da comunicação e de suas emoções, as pessoas se integram, o 
que resulta no encontro entre o sujeito e conhecimento, dando-se a consciência.

Quando se busca explicar o comportamento humano, identificam-se duas grandes forças que impulsionam a vida: sobrevivência e transcendência. A primeira é comum a todas as espécies e a segunda impulsiona a elaboração de sentido à própria existência. Elas dão origem ao conhecimento e definem o comportamento, pois, na busca de sobrevivência e de transcendência, desenvolve-se a comunicação (D'AMBROSIO, 2000).

\subsection{Alfabetismo / analfabetismo e privação cultural}

O fenômeno alfabetismo / analfabetismo, focado na perspectiva do desenvolvimento cultural do sujeito, pode ser analisado à luz dos estudos sobre Privação Cultural desenvolvidos por Reuven Feuerstein (1980). O conceito de Privação Cultural fundamenta-se na ausência de um tipo específico de transmissão cultural. Ela impede o desenvolvimento cognitivo e afetivo adequado e reduz o grau de modificabilidade e flexibilidade mental. A falta de um mediador ou de mediadores que se coloquem entre o sujeito e o mundo, que selecionem e organizem as informações contextualizando-as culturalmente, provoca a denominada síndrome cultural.

O baixo funcionamento cognitivo, o fraco rendimento informacional ou a desqualificação de alguns segmentos populacionais da sociedade, como, por exemplo, grupos étnicos ou grupos potencialmente excluídos, não são, segundo Feuerstein (1980), sinônimos de uma cultura inferior. É possível que a cultura de um povo seja muito rica economicamente, e sua capacidade informacional, contudo, seja muito baixa, com altas percentagens de insucesso e múltiplas dificuldades de aprendizagem, provocando problemas de inadaptação social.

Feuerstein (1980) observa que muitas pessoas estão "alienadas" em relação à própria cultura, em conseqüência de fatores sociais, psicofísicos, escolares e ambientais, o que constitui uma ruptura na transmissão cultural. Não basta falar de diferenças culturais definidas como comportamento deficiente, em razão da falta de familiaridade com as tarefas de aprendizagem, com estilos cognitivos, ou com conteúdos e modalidades de apresentação.

Vale ressaltar, portanto, o antagonismo que caracteriza o conflito educacional na atualidade: a necessidade de dependência para sobreviver e a de independência para a realização pessoal e existencial. Um indivíduo socializado numa cultura minoritária será culturalmente diferente dos membros da cultura predominante ou majoritária e poderá diferir dos outros em muitos traços culturais.

Desse modo, a multiplicidade de facetas do fenômeno alfabetismo, a variedade e a heterogeneidade de dimensões, a diversidade de relações com a sociedade e a com cultura levam a concluir não só que é impossível formular um conceito genérico e universal desse fenômeno, como também 
que são inúmeras as perspectivas teóricas e metodológicas de acordo com as quais se pode analisar essa questão. As perspectivas ora privilegiam a dimensão social, ora a dimensão individual, ora uma faceta, ora outra, a exemplo das perspectivas histórica, antropológica, sociológica, psicológica, sociolingüística, lingüística, discursiva, textual, literária, educacional e política; ou seja, a multirreferencialidade entendida como uma pluralidade de olhares dirigidos a uma realidade, uma pluralidade de linguagens para traduzir esta mesma realidade, e os olhares dirigidos a ela.

Sob a perspectiva do paradigma da complexidade, defendido por Morin (1994), a educação é entendida, no âmbito da abordagem multirreferencial:

[...] como uma função global, que atravessa o conjunto dos campos das ciências do homem e da sociedade, interessando tanto ao psicólogo como ao psicólogo social, ao economista, ao sociólogo, ao filósofo ou ao historiador etc. (ARDOINO, 1995, p.7).

À medida que os fenômenos educativos são apreendidos na sua complexidade, torna-se necessária uma abordagem que atente para essas várias perspectivas, reconhecendo suas recorrências e contradições, de tal forma que elas não se reduzam umas às outras.

\section{Considerações finais}

O progresso trazido pelo desenvolvimento científico e tecnológico impôs o surgimento de uma sociedade detentora de bom nível de escolaridade e cultura, preparada para usar os sofisticados produtos tecnológicos postos à sua disposição e, também, para continuar gerando inovações tecnológicas para atender à demanda da sociedade, bem como manter aquecida a economia.

A integração entre áreas do conhecimento, com vistas a compreender e intervir nos contextos sociais, coexistem na comunidade científica contemporânea. As revolucionárias condições de busca e disseminação da informação através de infovias, em especial a Internet, provocaram o surgimento de novas formas de conhecimento. A rapidez, a velocidade, a aceleração da pesquisa, geraram uma nova ordem na ciência em que se permite a participação cada vez maior do sujeito na compreensão do fenômeno que está investigando.

Depreende-se deste consenso que o profissional da informação, aquele cuja função é facilitar ao usuário o acesso à informação, precisa ser preparado para fazer a leitura da complexidade dos fenômenos sociais, o que pressupõe a compreensão e a conjugação de uma série de abordagens que integram diferentes áreas do conhecimento - a multirreferencialidade. Para tanto, o profissional da informação deve ser formado numa perspectiva plural, de modo a que possa entender o ambiente social e tecnológico em mudança e, assim, venha a desenvolver 
serviços informacionais que impulsionem o desenvolvimento dos seus usuários.

Isto porque, como apoiadores do processo de transferência e usabilidade da informação, a qual vai subsidiar a construção e desconstrução do conhecimento, estes profissionais, na função de mediadores, precisam levar seus usuários a desenvolverem as habilidades do observar, do analisar e do transcender; criando "pontes" e conexões com o mundo exterior, vivenciando a interdisciplinaridade e a contextualização, imprescindíveis ao desenvolvimento, e a internalização de uma atitude científica, o que reafirma a necessidade destes profissionais, de modo específico, de conhecer as teorias cognitivas.

Quanto às bibliotecas públicas e escolares brasileiras, cabe-lhes assumir, de modo planejado e efetivo, um compromisso com a educação, no sentido de ampliar a base intelectual da população, levando-a a desenvolver competências cognitivas complexas, necessárias ao domínio do conhecimento científico. Se, por um lado, este é um desafio a ser enfrentado pelos profissionais de informação, por outro, fica evidente a necessidade de qualificar estes profissionais, sendo requisito indispensável a sua iniciação nos estudos de cognição e mediação.

Por fim, vale ressaltar que é preciso investir na rede de bibliotecas, criando, para elas, políticas estruturantes e modelos funcionais atrelados à proposta de educação em vigor; definindo o papel e a ação da biblioteca na concepção e no desenvolvimento do currículo, tendo este, como essência, a aprendizagem permanente e colaborativa, incluindo o domínio de competências leitoras e informacionais, subsídios desencadeadores de criatividade e de inovação, e promotores de conhecimento.

\section{Referências}

ARDOINO, J. Multiréferentielle (analyse). In: ARDOINO, J. Le directeur et I'intelligence de l'organization: repéres et notes de lecture. Ivry: ANDES, 1995. p. 7-9.

BAPTISTA, S. G. A inclusão digital: programas governamentais e o profissional da informação - reflexões. Revista Inclusão Social, Brasília, v. 2, n. 2, P. 23-30, 2006.

BAUGHMAN, J. C. School libraries and MCAS scores. In: FIALHO, J. F.; ANDRADE, M. E. A. Comportamento informacional de crianças e adolescentes: uma revisão da literatura estrangeira. Ciência da Informação, v. 36, n. 1, p. 20-34, jan./abr. 2007 apud FIALHO, J. F.; ANDRADE, M. E. A. Comportamento Informacional de Crianças e Adolescentes: uma revisão da literatura estrangeira. Ciência da Informação, v. 36, n. 1, p. 20-34, jan./abr. 2007.

BIBLIOTECA Pública: princípios e diretrizes. Rio de Janeiro: Fundação Biblioteca Nacional, 2000. 160p. (Documentos técnicos, 6).

BRUNER, J. Atos de significação. Porto Alegre: Artes Médicas, 1997. 
D'AMBROSIO, U. Uma visão transdisciplinar. Pátis: Revista Pedagógica, Porto Alegre, v. 4, n. 13, p. 17-20, maio/jul. 2000.

FEUERSTEIN, R. Instrumental Enrichment: an Intervention Program for Cognitive Modifiability. Baltimore: University Park Press, 1980.

FREIRE, P. Educação e mudança. Rio de Janeiro: Paz \& Terra, 1979.

FIALHO, J. F.; ANDRADE, M. E. A. Comportamento Informacional de Crianças e Adolescentes: uma revisão da literatura estrangeira. Ciência da Informação, v. 36, n. 1, p. 20-34, jan./abr. 2007.

GARCEZ, E. M. S.; RADOS, G. J. V. Biblioteca Híbrida: um novo enfoque no suporte à educação a distância. Ciência da Informação, v. 31, n.2, p.44-51, maio/ago. 2002.

GOMES, H. E. Reforma curricular. [mensagem pessoal]. Mensagem recebida por marilene@ufba.br, em 30 out. 1999.

INSTITUTO BRASILEIRO DE GEOGRAFIA E ESTATÍSTICA (IBGE). Educação no Brasil. Disponível em: <http://www.ibge.gov.br/ibgeteen/ pesquisas/educacao.html>. Acesso em: 20 mar. 2009.

INSTITUTO BRASILEIRO DE GEOGRAFIA E ESTATÍSTICA (IBGE). Educação no Brasil. 2004-2005. Disponível em: <http://www.ibge.gov.br/ibgeteen/ pesquisas/educacao.html>. Acesso em: 20 mar. 2009.

INSTITUTO PAULO MONTENGRO - IPM. Indicador de Alfabetismo Funcional (INAF): Relatório 2007. São Paulo: IPM, 2007.

LE COADIC, Y. A ciência da informação. Brasília: Briquet de Lemos, 2004.

LEITE, C. ; MIRANDA, A.; SUAIDEN, E. A biblioteca híbrida na estratégia da inclusão digital na Biblioteca Nacional de Brasília. Inclusão Social, v. 3, n. 1, p. 17-23, out. 2007 / mar. 2008.

LONSDALE, M. Impact of school libraries on student achievement: a review of the research. Camberwell: Australian Council for Educational Research, 2003 apud FIALHO, J. F.; ANDRADE, M. E. A. Comportamento Informacional de Crianças e Adolescentes: uma revisão da literatura estrangeira. Ciência da Informação, v. 36, n. 1, p. 20-34, jan./abr. 2007.

MANGUEL, A. Uma história da leitura. São Paulo: Cia das Letras, 1997.

MINISTÉRIO DA EDUCAÇÃO E CULTURA (MEC). INSTITUTO NACIONAL DE ESTUDOS E PESQUISAS EDUCACIONAIS ANÍSIO TEIXEIRA (INEP). ENEM (Exame Nacional do Ensino Médio): Relatório pedagógico 2007. Brasília: MEC/Inep, 2007.

MORIN, E. Ciência com consciência. Lisboa: Publicações Europa-América, 1994.

- Os sete saberes necessários à educação do futuro. São Paulo: Cortez; Brasília: Unesco, 2000. 
ORGANIZAÇÃO DAS NAÇÕES UNIDADES (ONU). Declaração do Milênio. 2000. Disponível em: http://www.unric.org/html/portuguese/ uninfo/DecdoMil.pdf. Acesso em: 20 mar. 2009.

PIAGET, J. O nascimento da inteligência na criança. Rio de Janeiro: Guanabara, 1987.

TODD, R. J. Adolescents of the information age: patterns of information seeking and use, and implications for information professionals. School Libraries Worldwide, v. 9, n. 2, p. 27-46, 2003 apud FIALHO, J. F.; ANDRADE, M. E. A. Comportamento Informacional de Crianças e Adolescentes: uma revisão da literatura estrangeira. Ciência da Informação, v. 36, n. 1, p. 20-34, jan./abr. 2007.

VIGÓTSKI, L. S. A formação social da mente. São Paulo: Martins Fontes, 1991.

WITTROCK, M. Educational psychology, literacy, and reading comprehension. Educational Psychologist, v. 26, 1991 apud MANGUEL, A. Uma história da leitura. São Paulo: Cia das Letras, 1997. 